\title{
Proteinosis alveolar. Informe de dos casos y comentario bibliográfico
}

\author{
Tania I. Sánchez-Valadez,* Araceli Carrillo-Muñoz,* Alfredo Valero-Gómez,** Simón Martínez-Pérez,* \\ Abel Pérez-Rosales, * Carlos Núñez Pérez-Redondo, * Raúl Cicero-Sabido** ${ }^{*}$ \\ *Hospital General de México “Dr. Eduardo Liceaga”; $F$ Facultad de Medicina, UNAM. \\ Trabajo recibido: 18-VIII-2015; aceptado: 24-VIII-2015
}

\begin{abstract}
RESUMEN. La proteinosis alveolar es una enfermedad rara con incidencia estimada de 0.36 casos por millón de habitantes, razón hombremujer es 2,1: 1, con una mediana de edad de 51 años de edad. Dentro de los antecedentes de importancia se encuentran tabaquismo y exposición a polvos inorgánicos. Se considera como disfunción metabólica del surfactante caracterizada por la acumulación anormal de material proteináceo en los espacios alveolares con deterioro del intercambio gaseoso. Puede ser congénita, primaria o secundaria. El diagnóstico se sospecha por hallazgos clínicos y radiológicos caracterizado por áreas dispersas de atenuación alveolar en ground-glass o vidrio esmerilado. Las pruebas de función respiratoria sugieren patrón restrictivo. La fibrobroncoscopia es diagnóstica y terapéutica, con lavado broncoalveolar encontrando material lechoso, opaco y espumoso. La biopsia pulmonar puede ser útil en algunos casos. El lavado bronquioalveolar puede mejorar el cuadro clínico. Se presentan dos casos de proteinosis alveolar y su evolución clínica.
\end{abstract}

Palabras clave: Proteinosis alveolar, disfunción metabólica del surfactante, factor estimulante de colonias macrófago-granulocitos.

ABSTRACT. Alveolar proteinosis is a rare disease with an estimated incidence of 0.36 cases per million, male to female ratio is $2.1: 1$, with a median age of 51 years old. Among the important antecedents are smoking and exposure to inorganic dust. It is characterized by abnormal accumulation of proteinaceous material in the alveolar spaces with impaired gas exchange. Ranked in congenital, primary or secondary. The diagnosis is suspected on clinical and radiological findings characterized by alveolar attenuation scattered areas in ground -glass. Respiratory function tests suggest restrictive pattern. The diagnostic and therapeutic bronchoscopy is finding milky material, opaque and frothy. Lung biopsy may be useful in some cases. There are other treatments which are not yet standardized. We present 2 cases of alveolar proteinosis and its clinical evolution.

Key words: Granulocyte-macrophage colony-stimulating factor, pulmonary alveolar proteinosis, surfactant metabolism dysfunction.

\section{INTRODUCCIÓN}

La proteinosis alveolar pulmonar (PAP) es una enfermedad rara caracterizada por la acumulación anormal de material proteináceo en los espacios alveolares, con deterioro del intercambio gaseoso. ${ }^{1}$ Es más frecuente en adultos entre 20 y 50 años con disnea y tos no productiva. ${ }^{2}$ Se clasifica en congénita, de origen primario o secundario. ${ }^{3,4}$ El diagnóstico se realiza por el cuadro clínico, generalmente inespecífico, y los hallazgos de imagen; de manera definitiva por fibrobroncoscopia con lavado broncoalveolar con el hallazgo de líquido de aspecto lechoso, espumoso y cuerpos amiloides en el examen citológico. ${ }^{1,3,5}$ La biopsia pulmonar sólo es útil en algunos casos. La clínica y los hallazgos en la radiografía de tórax pueden ser indistinguibles de otras enfermedades respiratorias, pero la tomografía computarizada de alta resolución (TCAR) sugiere esta patología: con áreas dispersas de atenuación alveolar en ground-glass o vidrio esmerilado con superposición de engrosamiento lineal, septal inter e intralobular conocido como patrón crazypaving o «en empedrado». ${ }^{2}$ El lavado bronquioalveolar periódico mejora la sintomatología. El factor estimulante de colonias (GM-CSF) vía subcutánea e inhalado se ha usado en algunos casos como tratamiento. ${ }^{4}$ Se presentan dos casos con proteinosis alveolar.

\section{CASO 1}

Mujer de 25 años de edad con antecedente de exposición a acrílico en polvo durante un año. Inició sintomatología seis meses posteriores a la exposición al polvo, con cuadros infecciosos repetitivos tratados con múltiples antimicrobianos con disminución parcial del cuadro 
clínico. Presentó agudización de la sintomatología con progresión de la disnea a grado 2 en la escala Medical Research Council (MRC). ${ }^{6} \mathrm{~A}$ la exploración física signos vitales normales, temperatura de $36.1^{\circ} \mathrm{C}$, presión arterial $100 / 70 \mathrm{mmHg}$, frecuencia cardíaca de $80 / \mathrm{min}$, frecuencia respiratoria de 23 respiraciones/min, y saturación de hemoglobina con $75 \%$ de oxígeno en aire ambiente, la exploración física demostró estertores crepitantes inspiratorios diseminados en ambos hemitórax.

En examen de sangre biometría hemática normal, química sanguínea sin alteraciones. Gasometría arterial en aire ambiente reveló pH 7.4, PO2 50 mmHg, PCO2 34 $\mathrm{mmHg}, \mathrm{SO} 275 \%$ y $\mathrm{HCO} 324 \mathrm{mmHg}$. Anticuerpos antinucleares y factor reumatoide normales. Espirometría y pletismografía con patrón restrictivo muy grave. Volumen espiratorio forzado al primer segundo (VEF1) $0.98 \mathrm{~L}(31 \%)$, VEF1/FVC de $116 \%$, capacidad vital forzada (FVC) 0.99 $\mathrm{L}(26 \%)$ del predicho, capacidad pulmonar total $1680 \mathrm{~mL}$ (31\%), volumen residual $630 \mathrm{~mL}(32 \%)$, con disminución de la difusión para el monóxido de carbono (DLCO 34\% de lo previsto). En caminata de seis minutos recorrió 350 m presentando disnea Borh 3-4 con saturación $89 \%$ con oxígeno, ya que presentaba saturación $72 \%$ aire ambiente.

Los cultivos de expectoración fueron negativos en examen micológico, bacteriológico y micobacteriológico, incluyendo nocardia. La radiografía de tórax mostró infiltrados alveolares bilaterales y la TCAR con engrosamiento en septos interlobulillares de predominio periférico bilateral con opacidades cotonosas en mosaico y otras en vidrio esmerilado (figura 1). Se realizó fibrobroncoscopia con lavado broncoalveolar (BAL) aspirando material lechoso y espumoso (figuras $2 \mathrm{~A}$ y B). No hubo anomalías endobronquiales. Por citología se encontraron linfocitos, material proteináceo y macrófagos alveolares (figura 3). Se realizó el diagnóstico de proteinosis alveolar. Se efectuaron dos BAL en un período de tres meses con mejoría parcial del cuadro, por lo cual se instauró tratamiento con GM-CSF por vía subcutánea, sin presentar mejoría clínica. Actualmente continúa en tratamiento con BAL cada dos a tres meses.

\section{CASO 2}

Paciente femenino de 53 años de edad, sin antecedentes de importancia, un hermano con tuberculosis pulmonar. Su padecimiento se inició cinco meses antes de su ingreso al hospital, presentó malestar general, disnea mMRC 2, tos en accesos, sin expectoración, dolor opresivo en cara anterior de tórax. Saturación de oxígeno de $80 \%$ al aire ambiente, ruidos respiratorios con estertores crepitantes, de predominio en regiones infraescapulares, en ambos hemitórax. Acropaquia y edema de miembros inferiores ++. La radiografía de tórax con infiltrados reticulonodulares de predominio en las regiones basales, con algunas zonas de consolidación. TCAR con zonas en vidrio despulido sobrepuestas con engrosamiento reticular inter e intralobulillar basal, parahiliares, bilateral (figura 4). Se realizó biopsia pulmonar con diagnóstico de proteinosis alveolar, probablemente congénita encontrando material eosinófilo acelular en espacios alveolares tinción H/E (figura 5A) y material con tinción PAS positivo (figura 5B). Se inició tratamiento con BAL en promedio cada cuatro meses, con disminución de la sintomatología. A dos años y medio del diagnóstico la paciente se encuentra estable.

\section{DISCUSIÓN Y COMENTARIO BIBLIOGRÁFICO}

Se presentan dos casos de proteinosis alveolar, el primero secundario a inhalación de polvo para uñas postizas, en tratamiento con BAL con mejoría discreta y GM-CSF vía subcutánea sin mejoría; el segundo caso corresponde a proteinosis alveolar con respuesta clínica favorable.
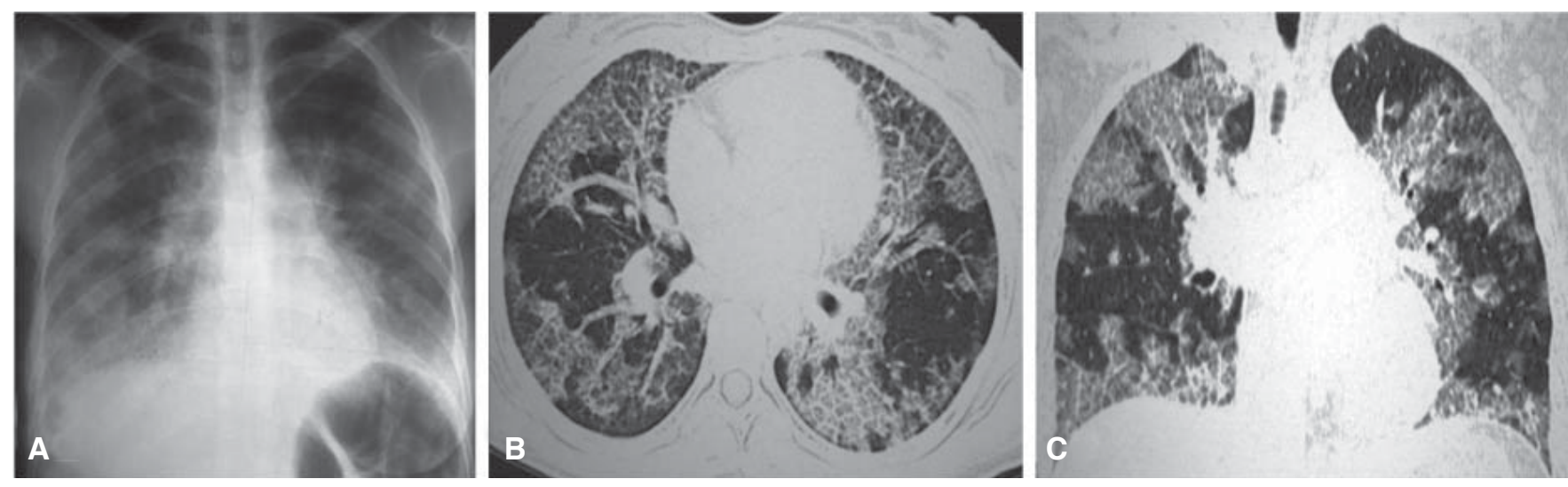

Figura 1. Caso 1. A. Radiografía de tórax; B. Tomografía computarizada de alta resolución de tórax corte axial; C. Tomografía computarizada de alta resolución de tórax corte coronal. Se observan opacidades en vidrio esmerilado bilaterales. 
La proteinosis alveolar es una enfermedad rara, aún producida por acumulación de material surfactante en los alvéolos respiratorios lo que condiciona deterioro en el intercambio gaseoso. ${ }^{1}$ El surfactante disminuye la tensión superficial de la interfase entre aire-líquido de la pared alveolar, evitando así el colapso alveolar, lo componen 90\% fosfolípidos (fosfatidilcolina), $10 \%$ proteínas del tipo A, B, C y $D$ y menos $1 \%$ carbohidratos..$^{3-7}$ Los fosfolípidos y proteínas del factor surfactante se sintetizan, almacenan, y se secretan en alvéolos por los neumocitos tipo II y se eliminan por la fagocitosis de macrófagos alveolares. ${ }^{7}$
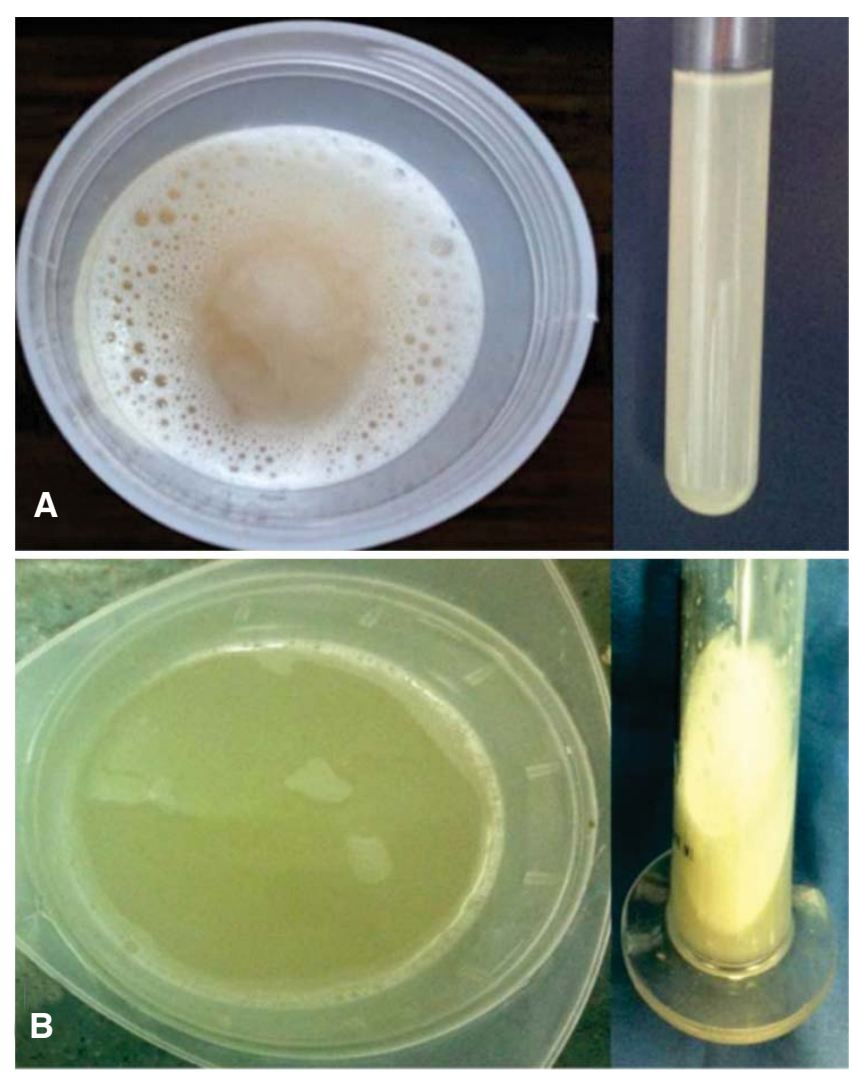

Figura 2. Líquido de lavado bronquioalveolar con alto contenido proteináceo. A. Caso 1, B. Caso 2.
La razón hombre-mujer es 2.1:1, con una mediana de edad de 51 años de edad, $56 \%$ tienen antecedentes de tabaquismo, y $23 \%$ a exposición a polvos. ${ }^{8}$ Su incidencia estimada es de 0.36 casos por millón de habitantes. ${ }^{9}$

Esta enfermedad se clasifica en congénita, primaria y secundaria. ${ }^{3,4}$ La forma congénita comprende un grupo heterogéneo de trastornos causados por mutaciones en los genes que codifican la proteína del surfactante B o $C$ de la beta $c$ en el receptor de factor estimulante de colonias de granulocitos-macrófagos (GM-CSF) tales como mutaciones en SFTP-C ${ }^{10,11}$ y en el receptor b o a del factor estimulante de colonias (GMCS). ${ }^{9-11}$

La forma primaria o autoinmune es idiopática ${ }^{3,4}$ se relaciona con alta concentración de anticuerpos anti-GM-CSF de inmunoglobulina (Ig) G. ${ }^{12,13}$ Los anticuerpos anti-GMCSF se unen GM-CSF con alta afinidad, bloqueando su actividad. Debido a la reducción o ausencia de estímulo en GM-CSF, los macrófagos alveolares son incapaces de fagocitar el factor surfactante. ${ }^{3,4} \mathrm{La}$ secundaria se desarrolla generalmente en asociación con enfermedades relacionadas con el deterioro funcional o reducción del número de macrófagos alveolares, entre ellas se encuentran condiciones como inmunosupresión farmacológica, la inhalación de polvos inorgánicos (p. ej. sílice) como el caso que se presenta, gases tóxicos o algunas infecciones, la cual corresponde a $90 \%$ de los casos. 3,4

El curso clínico de la enfermedad es variable, desde asintomático hasta casos con insuficiencia respiratoria. En una cohorte japonesa de proteinosis alveolar primaria encontraron disnea de esfuerzo (39\%), disnea y tos (11\%), o tos $(10 \%) .{ }^{8}$ Con menor frecuencia fiebre, dolor torácico o hemoptisis y principalmente asociados a infección pulmonar concomitante. $., 7,8 \mathrm{Un}$ tercio de los pacientes es asintomático. ${ }^{3} \mathrm{~A}$ la exploración física se encuentran estertores inspiratorios en $50 \%$ de los pacientes, cianosis en $25 \%$.

Las imágenes radiográficas de tórax muestran infiltrados perihiliares a veces confluentes de predominio en bases pulmonares, mal definidos en mosaico y en vidrio esmerilado 3,4 simulando "alas de mariposa».,7 Es importante establecer ausencia de derrame pleural, adenopatías y cardiomegalia. ${ }^{3,4}$

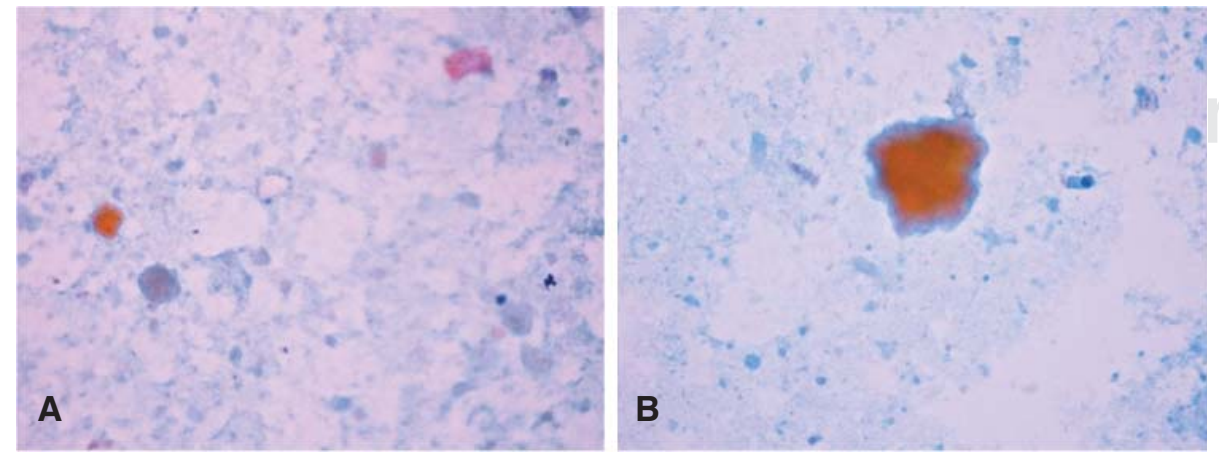

Figura 3. A y B.

Citología de lavado bronquial. Se observan sobre un fondo proteináceo escasos macrófagos espumosos. Estos hallazgos sugieren proteinosis alveolar. Tinción Papanicolaou. 

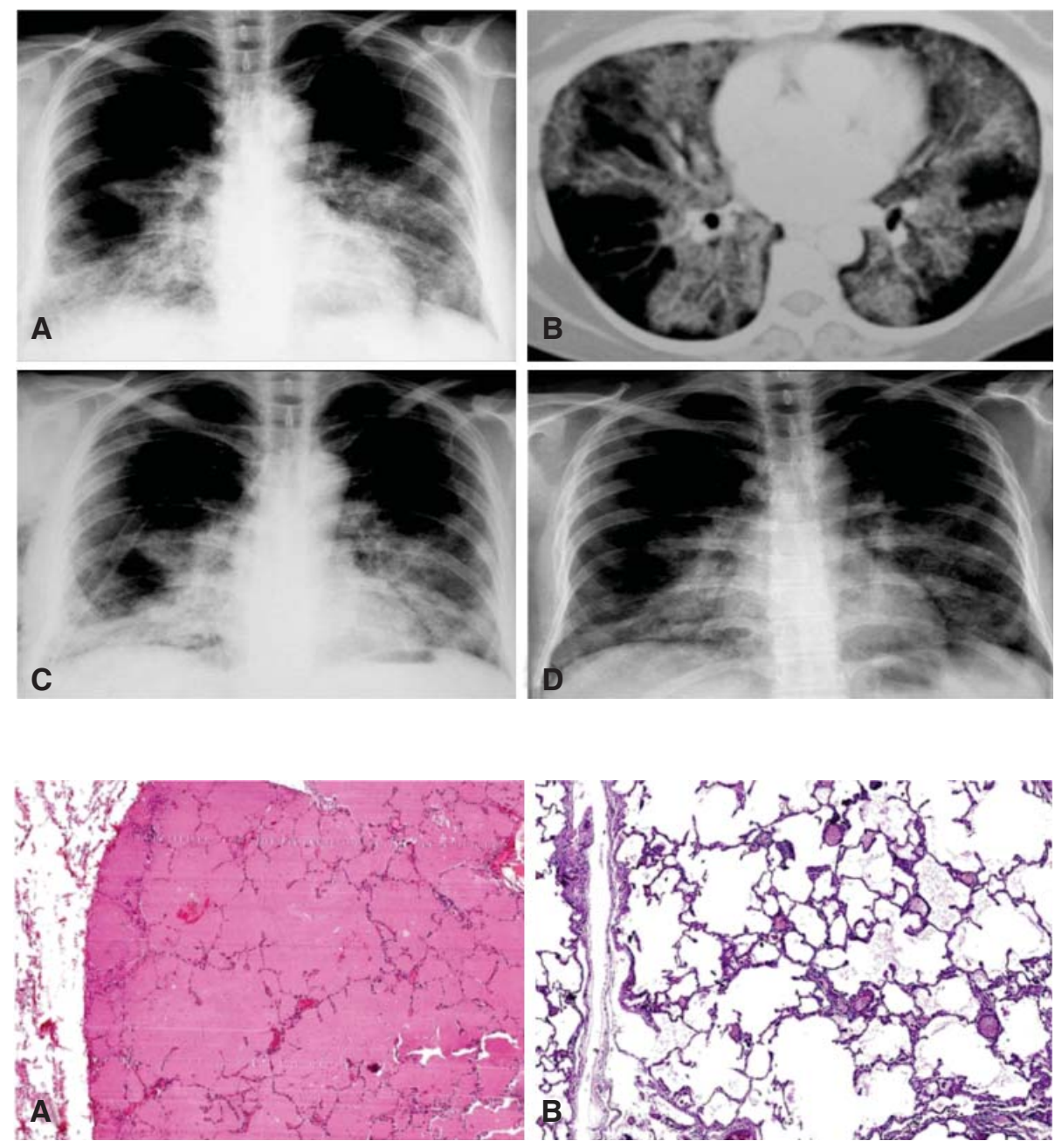

\section{Figura 5.}

Caso 2. A. Biopsia de pulmón. Se observan espacios alveolares ocupados por material eosinófilo que corresponden a proteinosis. Tinción H-E; B. Biopsia de pulmón. Hay escaso material proteináceo que es altamente sugestivo de proteinosis. Tinción de PAS.
La TCAR muestra imágenes en vidrio esmerilado caracterizado por «patrón en pavimentación» (crazypaving), engrosamiento septal, interlobular e interlobulillar en mosaico con áreas adyacentes normales. ${ }^{4,7}$ No hay adenopatías mediastinales ni nódulos pulmonares. ${ }^{3}$

Los exámenes de sangre y de orina son normales. En algunas ocasiones aumentan lactato deshidrogenasa, en otras el antígeno carcinoembrionario, citoqueratina, mucinaKL-6 y el factor tenso activo $A, B$, y $D$ aunque son de poco valor pronóstico. ${ }^{7,12-14}$ Los resultados de las pruebas de función pulmonar pueden ser normales, o mostrar un patrón restrictivo con disminución en difusión de monóxido de carbono. ${ }^{7}$

En $75 \%$ de los casos sospechosos, los hallazgos patológicos en el BAL pueden establecer el diagnóstico en el líquido alveolar que se encuentra opaco de aspecto lechoso, espumoso; con aumento de macrófagos alveolares y predominio de linfocitos. ${ }^{3,7}$

La biopsia pulmonar teñida con PAS muestra espacios alveolares llenos de material amorfo granular acidófilo que se tiñe de rosa, PA Schiff positivo. La arquitectura del pulmón se mantiene aunque puede presentar datos de fibrosis. ${ }^{4,7}$ El líquido de BAL puede mostrar linfocitosis. ${ }^{4}$ La inmunohistoquímica revela acumulación de proteína del factor surfactante. ${ }^{7}$ La biopsia abierta de pulmón es el estándar de oro para el diagnóstico de PAP, pero no siempre es necesario realizarla. ${ }^{4,7}$

La microscopia electrónica muestra que el material intraalveolar contiene cuerpos lamelares que son desechos granulares amorfos membranosos de $4.7 \mathrm{~nm}$ que semejan la mielina tubular. ${ }^{3,15}$

Los anticuerpos anti-GM-CSF son específicos, los cuales se cuantifican por ELISA siendo diagnósticos a una concentración de $0.19 \mu \mathrm{g} / \mathrm{mL}$ es específica de proteinosis alveolar y una concentración de $0.10 \mathrm{mg} /$ $\mathrm{mL}$ tiene alto valor predictivo negativo. ${ }^{3,7}$

Las pruebas de la función pulmonar y caminata de seis minutos son importantes para la decisión terapéutica. La espirometría muestra con frecuencia patrón restrictivo, pero puede dar resultados normales en 10- 
$30 \%$ de casos. La presión arterial de oxígeno (paO2) y la DLCO están disminuidas (40-50\%). ${ }^{3}$ En caminata de 6 minutos se presenta desaturación de hemoglobina. ${ }^{3}$

El tratamiento más aceptado es el $\mathrm{BAL}^{3,5}$ con el fin de extraer el material proteináceo que ocupa el espacio aéreo, siendo diagnóstico y terapéutico. ${ }^{1}$ Esta técnica está indicada cuando hay un diagnóstico histológico definitivo y $\mathrm{PaO} 2$ menor de $65 \mathrm{mmHg}$, gradiente alvéolo arterial mayor de $40 \mathrm{mmHg}$, presencia de un cortocircuito mayor de $12 \%$ y disnea en reposo. ${ }^{1}$

Seymour et al. ${ }^{9}$ indican que la sobrevida a cinco años a partir del diagnóstico es mayor en los que se realiza BAL periódico que en los que no se realiza (DE $94+2$ vs. $85+5 \%)$; datos basados en un estudio $(n=231)$ en el que se les realizó lavado bronquioloalveolar a 146 pacientes y a 85 no. ${ }^{9}$ Sin embargo, no existen estudios sistemáticos de la técnica utilizada en la práctica clínica.

También se ha utilizado GM-CSF vía subcutánea o inhalada presentando mejoría en $\mathrm{PaO} 2$ de $9 \mathrm{mmHg}{ }^{7}$ sin embargo, no se ha demostrado disminución de anticuerpos del factor estimulante de colonias, ${ }^{3}$ no se ha estandarizado su uso y se reportan resultados controversiales. ${ }^{4}$ También se han utilizado rituximab y plasmaféresis, aunque la efectividad de estos tratamientos no está clara. ${ }^{3}$

En el caso 1 se realizaron dos lavados bronquioalveolares en un lapso de tres meses, con mejoría parcial de la sintomatología, por lo que se inició tratamiento con GM-SCF sin mejoría, requiriendo nuevos BAL. En el segundo caso se realizó BAL intermitente con buena respuesta clínica.

La comprensión acerca de esta patología ha aumentado considerablemente en la última década a partir de estudios en ratones y en humanos. El retraso en el diagnóstico es debido a su presentación clínica variable e inespecífica.

Se requieren más estudios para comprender la patogenia de esta patología, lo que permitirá mejorar y realizar tempranamente el diagnóstico y tratamiento del paciente.

\section{REFERENCIAS}

1. Rodríguez PJA, Rodríguez BE, Sánchez GA. Proteinosis alveolar. Respuesta al tratamiento con factor estimulante de colonias de granulocitos y macrófagos por vía inhalada. Arch Bronconeumol 2009;45(3):150-152.

2. De Arriba C, Antón C, Arreche E, Lorente MP. Proteinosis alveolar pulmonar y patrón en empedrado («crazy-paving») en tomografía computarizada de alta resolución. Anales Sis San Navarra 2006;29(1):127-130.

3. Borie R, Danel C, Debray M-P, et al. Pulmonary alveolar proteinosis. Eur Respir Rev 2011;20(120):98-107. doi: 10.1183/09059180.00001311.
4. Huizar I, Kavuru MS. Alveolar proteinosis syndrome: pathogenesis, diagnosis, and management. Curr Opin Pulm Med 2009;15(5):491-498. doi: 10.1097/ MCP.0b013e32832ea51c.

5. Cai C, Ye M, Xu H, Li Y. Pulmonary alveolar proteinosis treatment by whole-lung lavage. Postgrad Med J 2012;88(1042):492-493. doi: 10.1136/postgradmedj-2011-130620.

6. Mahler DA, Wells CK. Evaluation of clinical methods for rating dyspnea. Chest 1988;93(3):580-586.

7. Trapnell BC, Whitsett JA, Nakata K. Pulmonary alveolar proteinosis mechanisms of disease. N Engl J Med 2003;349(26):2527-2539.

8. Inoue Y, Trapnell BC, Tazawa R, et al.; Japanese Center of the Rare Lung Diseases Consortium. Characteristics of a large cohort of patients with autoimmune pulmonary alveolar proteinosis in Japan. Am J Respir Crit Care Med 2008;177(7):752-762. doi: 10.1164/rccm.200708-12710C.

9. Seymour JF, Presneill JJ. Pulmonary alveolar proteinosis: progress in the first 44 years. Am J Respir Crit Care Med 2002;166(2):215-235.

10. Brasch F, Griese M, Tredano M, et al. Interstitial lung disease in a baby with a de novo mutation in the SFTPC gene. Eur Respir J 2004;24(1):30-39.

11. Nogee LM, Dunbar AE 3rd, Wert S, Askin F, Hamvas A, Whitsett JA. Mutations in the surfactant protein $C$ gene associated with interstitial lung disease. Chest 2002;121(3 Suppl):20S-21S.

12. Notarangelo LD, Pessach I. Out of breath: GM-CSFR alpha mutations disrupt surfactant homeostasis. J Exp Med 2008;205(12):2693-2697. doi: 10.1084/ jem.20082378.

13. Suzuki T, Sakagami T, Rubin BK, et al. Familial pulmonary alveolar proteinosis caused by mutations in CSF2RA. J Exp Med 2008;205(12):2703-2710. doi: 10.1084/ jem.20080990.

14. Martinez-Moczygemba M, Doan ML, Elidemir O, et al. Pulmonary alveolar proteinosis caused by deletion of the GM-CSFR alpha gene in the $X$ chromosome pseudoautosomal region 1. J Exp Med 2008;205(12):2711-2716. doi: 10.1084/jem.20080759.

15. Travis WD, Rosado-de-Christensen ML, Colby TV, Koss MN, Müller NL, King Jr TE. Pulmonary alveolar proteinosis. In: Travis WE, Colby TV, KossMN, et al., editors. Non-neoplasic diseases of the lower respiratory tract. Washington: American Registry of Pathology; 2002.p.169-176.

\section{$\triangle$ Correspondencia:}

Dr. Raúl Cicero Sabido

Hospital General de México «Dr. Eduardo Liceaga».

Balmis Núm. 142, Colonia Doctores, 06720,

Cuauhtémoc, México, D.F., Tel. 50043857

Correo electrónico: rc1neumo@unam.mx

Los autores declaran no tener conflictos de intereses. 